\title{
PSO Assisted AdAPTIVE Force ConTrol IN MiLLING
}

\author{
CUS, F. \& ZUPERL, U.
}

Abstract: A combination of off-line feedrate prediction based on swarm intelligence and online adaptive force control is used to maintain a reference peak force during milling for efficient machining. In this paper, a new evolutionary computation technique, particle swarm optimization (PSO), is proposed and implemented to efficiently and robustly optimize machining parameters simultaneously. Feedrate optimization algorithms use geometry and force model to calculate recommended feedrates for each tool move, based on a reference peak force. An artificial neural networks (ANN) predictive model for critical process parameters is used to predict the surface of cutting force which in turn is used by the PSO developed algorithm to optimize the feedrate subject to a comprehensive set of constraints. The adaptive controller adjusts the feedrate during machining to maintain the reference peak force. It is the combination of these methods that yields accurate force control.

Key words: end-milling, adaptive control, optimization, cutting force
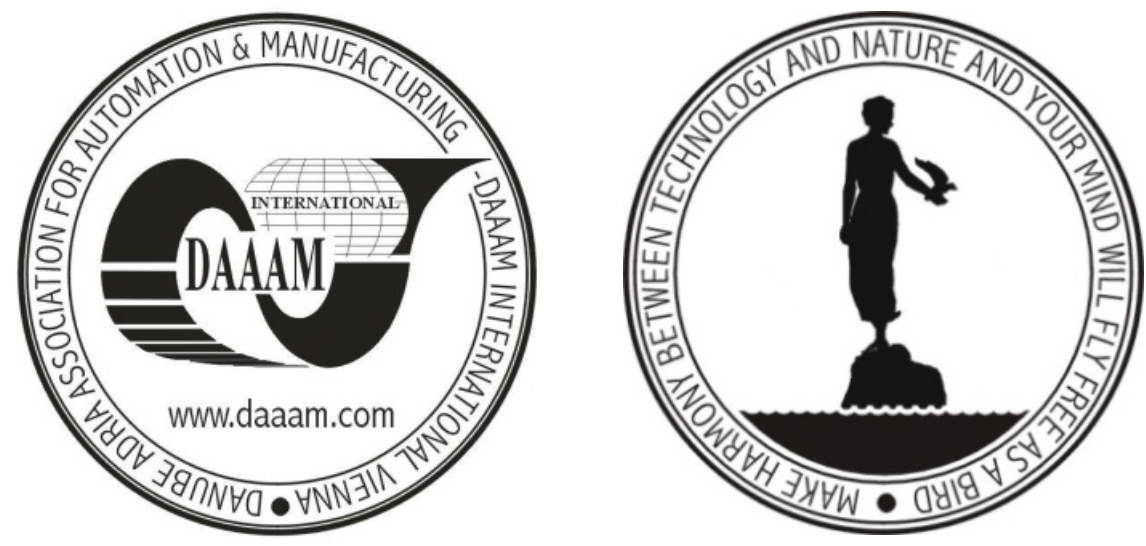

Authors' data Univ.Prof. Cus, F[ranc]; Dr. Sc. Zuperl, U[ros], University of Maribor, Faculty of mechanical engineering, Smetanova 17, 2000 Maribor, Slovenia, uros zuperl@uni-mb.si, franc.cus@uni-mb.si.

This Publication has to be referred as: Cus, F[ranc] \& Zuperl, U[ros] (2009). PSO Assisted Adaptive Force Control in Milling, Chapter 03 in DAAAM International Scientific Book 2009, pp. 017-024, B. Katalinic (Ed.), Published by DAAAM International, ISBN 978-3-901509-69-8, ISSN 1726-9687, Vienna, Austria DOI: $10.2507 /$ daaam.scibook.2009.03 